Provided for non-commercial research and education use. Not for reproduction, distribution or commercial use.

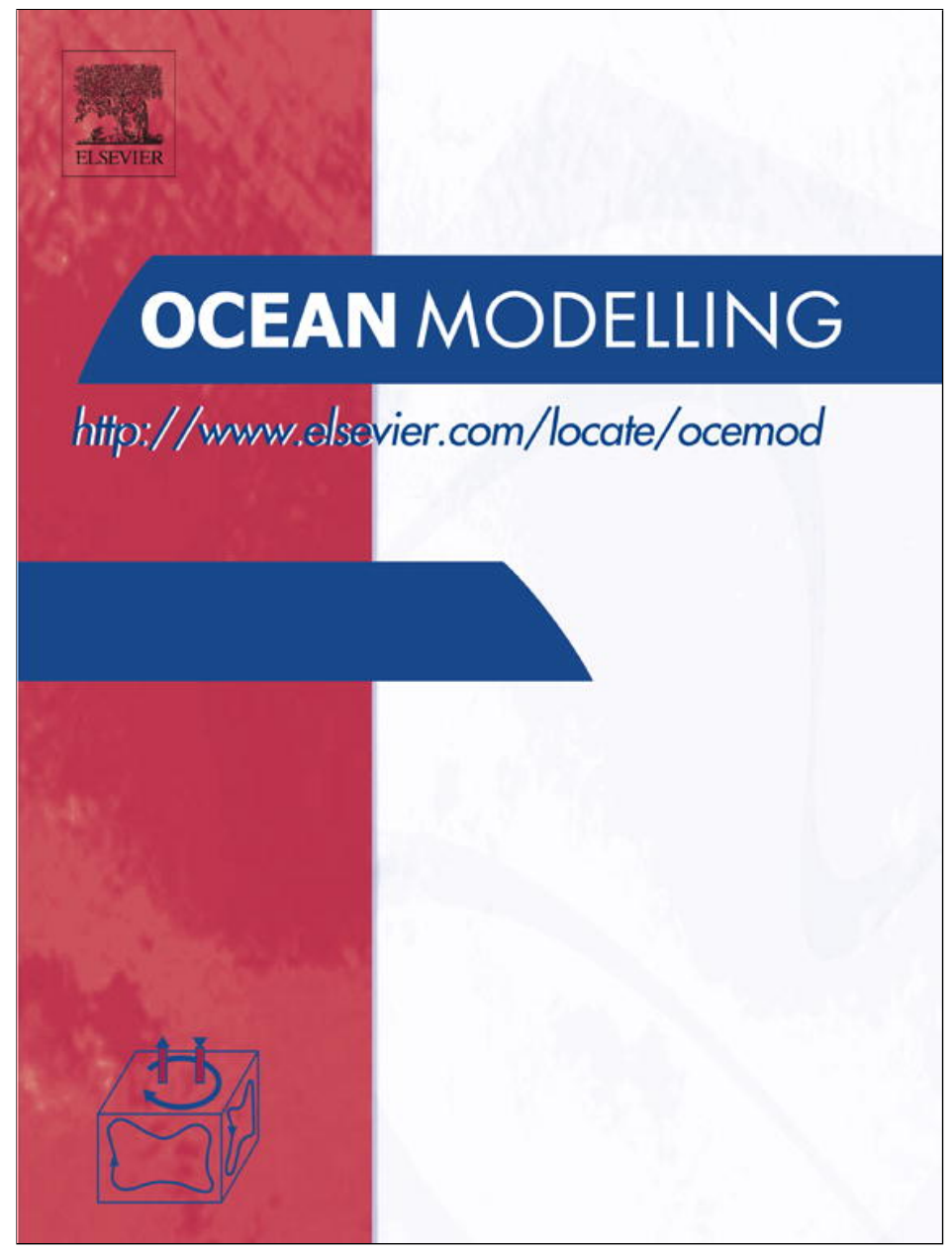

(This is a sample cover image for this issue. The actual cover is not yet available at this time.)

This article appeared in a journal published by Elsevier. The attached copy is furnished to the author for internal non-commercial research and education use, including for instruction at the authors institution and sharing with colleagues.

Other uses, including reproduction and distribution, or selling or licensing copies, or posting to personal, institutional or third party websites are prohibited.

In most cases authors are permitted to post their version of the article (e.g. in Word or Tex form) to their personal website or institutional repository. Authors requiring further information regarding Elsevier's archiving and manuscript policies are encouraged to visit:

http://www.elsevier.com/copyright 


\title{
A model reconstruction of the Antarctic sea ice thickness and volume changes over 1980-2008 using data assimilation
}

\author{
François Massonnet ${ }^{\mathrm{a}, *}$, Pierre Mathiot $^{\mathrm{b}}$, Thierry Fichefet ${ }^{\mathrm{a}}$, Hugues Goosse ${ }^{\mathrm{a}}$, Christof König Beatty ${ }^{\mathrm{a}}$, \\ Martin Vancoppenolle ${ }^{\mathrm{c}}$, Thomas Lavergne ${ }^{\mathrm{d}}$ \\ ${ }^{a}$ Georges Lemaître Centre for Earth and Climate Research, Earth and Life Institute, Université catholique de Louvain, Louvain-la-Neuve, Belgium \\ ${ }^{\mathrm{b}}$ British Antarctic Survey, National Environment Research Council, Cambridge, United Kingdom \\ ${ }^{\mathrm{c}}$ Laboratoire d'Océanographie et du Climat (Expérimentations et Approches Numériques), Institut Pierre-Simon Laplace, Paris, France \\ ${ }^{\mathrm{d}}$ Norwegian Meteorological Institute, Oslo, Norway
}

\section{A R T I C L E I N F O}

\section{Article history:}

Received 25 September 2012

Received in revised form 7 January 2013

Accepted 10 January 2013

Available online 1 February 2013

\section{Keywords:}

Antarctic

Sea ice thickness and volume

Data assimilation

EnKF

Trends

Variability

Southern Ocean

\begin{abstract}
A B S T R A C T
Sea ice variability in the Southern Ocean has a complex spatio-temporal structure. In a global warming context, the Antarctic sea ice cover has slightly expanded over the recent decades. This increase in sea ice extent results, however, from the sum of positive and negative regional trends and is influenced by a wide range of modes of climate variability. An additional view on sea ice thickness and volume changes would improve our understanding. Still, no large-scale multi-decadal well-sampled record of Antarctic sea ice thickness exists to date. To address this issue, we assimilate real sea ice concentration data into the ocean-sea ice model NEMO-LIM2 using an ensemble Kalman filter and demonstrate the positive impacts on the global sea ice cover. This paper reports the 1980-2008 evolution (monthly anomalies, trends plus their uncertainty ranges) of sea ice volume and thickness in different sectors of the Southern Ocean. We find that the global Antarctic sea ice volume has risen at a pace of $355 \pm 338 \mathrm{~km}^{3} / \mathrm{decade}$ $(5.6 \pm 5.3 \% /$ decade $)$ during this period, with an increase in the Ross and Weddell Seas $(150 \pm 124$ and $209 \pm 362 \mathrm{~km}^{3} /$ decade, respectively) and a decrease in the Amundsen-Bellingshausen Seas $\left(-45 \pm 54 \mathrm{~km}^{3} /\right.$ decade). Sea ice volume anomalies co-vary well with extent anomalies, and exhibit yearly to decadal fluctuations. The results stress the need to analyze sea ice changes at the regional level first and then at the hemispheric level.
\end{abstract}

(C) 2013 Elsevier Ltd. All rights reserved.

\section{Introduction}

Satellite observations have revealed a slight increase in Antarctic sea ice extent over the recent decades (Comiso and Nishio, 2008; Parkinson and Cavalieri, 2012). The full picture of the recent Antarctic sea ice variability should not, however, be reduced to this simple statistic. This positive trend averaged over the whole hemisphere results indeed from both positive and negative contributions operating at smaller spatial scales. Despite an apparently simple zonal symmetry in the seasonal development of the ice cover, the interannual variability of Antarctic sea ice concentration is indeed far from being annular (Liu et al., 2004; Lefebvre and Goosse, 2008; Comiso and Nishio, 2008; Turner et al., 2009; Stammerjohn et al., 2012). A closer look at these contrasted regional responses of sea ice is therefore probably a first and necessary step to gain insight into the global counter-intuitive overall increase in Antarctic sea ice in a global warming context.

\footnotetext{
* Corresponding author. Tel.: +32 10473067 .

E-mail address: francois.massonnet@uclouvain.be (F. Massonnet).

URL: http://www.climate.be/u/fmasson (F. Massonnet).
}

Ice areal coverage is easily observed from space. However, it only derives from the more fundamental changes in the ice thickness distribution. Ice thickness provides a more complete description of the ongoing changes in the mass balance of the sea ice cover. Yet, monitoring the ice thickness is challenging due to (i) the remote location of polar regions, and (ii) the difficulty of satellites signals to penetrate through the sea ice. In the Arctic, Upward Looking Sonar and satellite data (Rothrock et al., 2008; Kwok and Rothrock, 2009) as well as ice mass balance buoys data (RichterMenge et al., 2006) revealed a substantial thinning of the ice pack during the previous decades, consistent with the better documented area decrease (e.g., Cavalieri et al., 2003; Cavalieri and Parkinson, 2012). In the Southern Ocean, the compilation of Worby et al. (2008) contains about 14,000 visual ship-based estimates of sea ice thickness around Antarctica. Unfortunately, this dataset is characterized by large spatio-temporal gaps (Worby et al., 2008). Other initiatives exist from ice chart data (DeLiberty et al., 2011) and satellite campaigns (Zwally et al., 2008; Yi et al., 2011; Kurtz and Markus, 2012), but they are often limited to a portion of the Southern Ocean and/or for a limited duration. All together, these highly valuable observations can thus provide, in some regions, 
estimates of the seasonal variations in Antarctic ice thickness. They are not sufficient, however, to provide a long-term view on global and regional changes in Antarctic ice thickness.

Modelling tools are in this respect informative surrogates to observations. Atmosphere-ocean general circulation models (AOGCMs) give, among others, gridded and continuous information about sea ice concentration and thickness. Still, a recurrent shortcoming of these models is their difficulty to reproduce the statistical properties of the interannual variability of the Southern Hemisphere sea ice cover. For instance, these models tend to simulate negative trends and to overestimate the variance of the sea ice extent (Arzel et al., 2006; Connolley and Bracegirdle, 2007; Holland and Raphael, 2006; Zunz et al., 2012). As a consequence, the confidence is low in the global sea ice thickness and volume decadal reconstructions provided by AOGCMs. Prescribing the atmospheric forcing can partly correct the models biases. Fichefet et al. (2003a,b) and Zhang (2007) proposed multi-decadal reconstructions of the global Antarctic sea ice volume using ocean-sea ice models forced by atmospheric reanalyses. Still, the reliability of these sea ice reconstructions is heavily dependent on the atmospheric forcing which is known to be of questionable quality in the Southern Ocean (Vancoppenolle et al., 2011; Massonnet et al., 2011).

In the present work, we propose to follow a hybrid approach, i.e. data assimilation, in order to investigate the large-scale changes in Antarctic sea ice thickness and volume over the past three decades. Loosely speaking, data assimilation aims at combining model forecasts (here obtained from the ocean-sea ice model NEMO-LIM2) with observations (here, passive microwave observations of sea ice concentration) in some consistent manner (here, prescribed following the ensemble Kalman filter theory) as to produce an optimal analysis state. The description of the methods is given in Section 2 . Then, we consider the run with data assimilation and show how the ensemble Kalman filter acts on the major biases of the run without data assimilation (Section 3 ). We present and discuss our reconstruction of spatial changes in ice thickness and volume in Section 4, before the conclusions (Section 5). For the sake of consistency, we present as supplementary material our reconstruction of the Arctic sea ice thickness and volume changes over 1980-2008. This reconstruction is consistent with another reanalysis (Schweiger et al., 2011) but is not discussed in this paper, whose attempt is to provide a first and novel view on Antarctic sea ice thickness changes during the previous decades using data assimilation.

\section{Methods}

NEMO-LIM2 is a global ocean-sea ice model well suited for climate studies. In the present case, it is forced by atmospheric reanalyses and various climatologies. In addition, an ensemble Kalman filter (EnKF) scheme is implemented in the standard model configuration and observations of sea ice concentration are assimilated.

\subsection{Ocean-sea ice model and atmospheric forcing}

The two main building blocks of NEMO-LIM2 are the global oceanic general circulation model (OGCM) OPA9 Océan PArallélisé, version 9: Madec, 2008 and the sea ice model LIM2 Louvain-laNeuve sea Ice Model, version 2: (Fichefet and Morales Maqueda, 1997; Timmerman et al., 2005).

OPA is a finite difference, hydrostatic, primitive equation global OGCM adapted to large-scale simulations. The model equations are solved on the ORCA2 tripolar grid $\left(\sim 2^{\circ}\right.$, with mesh refinement near the equator and at the poles) in its 31 vertical level configuration. A leapfrog scheme is used for time stepping. Surface boundary layer mixing and interior vertical mixing are parameterized according to a turbulent kinetic energy closure scheme. The bottom boundary layer parameterization is based on Beckmann and Döscher (1997). An exhaustive description of OPA can be found in Madec (2008).

LIM2 is a dynamic-thermodynamic sea ice model. Semtner (1976) 3-layer ( 2 of ice and 1 of snow) formulation is used to compute the vertical profile of temperature within the snow-ice pack. LIM2 includes parameterizations of lateral melting and heat storage by brine pockets. The model does not explictly resolve the ice thickness distribution but assumes a uniform distribution of ice thickness between zero and twice its mean value in each grid cell. When the load of snow on top of sea ice is large enough to depress the snow-ice interface below sea level, the model simulates the formation of snow ice. Ice dynamics are treated by considering sea ice as a two-dimensional viscous-plastic continuum (Hibler, 1979), and the momentum equations are solved on a B-grid. See Fichefet and Morales Maqueda (1997) or Timmerman et al. (2005) for additional information about the sea ice model.

The ice and ocean components (together referred to as NEMO-LIM2 from now) are coupled following the formulation of Goosse and Fichefet (1999). NEMO-LIM2 is forced by daily near-surface air temperatures and $u, v$ - wind speeds from the NCEP/NCAR reanalysis project (Kalnay et al., 1996), as well as monthly climatologies of relative humidity (Trenberth et al., 1989), total cloudiness (Berliand and Strokina, 1980) and precipitation (Xie and Arkin, 1997). We follow the empirical parameterizations described in Goosse (1997) to prescribe the atmosphere-sea ice turbulent and radiative heat fluxes. River runoff rates are prescribed from the climatological dataset of Baumgartner and Reichel (1976) combined with a mean seasonal cycle derived from the Global Runoff Data Centre data (GRDC, 2000). A weak (time scale of 1 year) restoring term is added in the surface freshwater budget equations to prevent the model from drifting away from its climatology. The ocean time step is $5760 \mathrm{~s}=1 / 15$ day and the sea ice model is called every 5 ocean time steps.

\subsection{Ensemble Kalman filter and data assimilation}

All data assimilation techniques follow one common objective: to provide an optimal statistical estimate, or "analysis", of a system. Nonetheless, many different possible implementations exist to achieve this objective. Current data assimilation methods in sea ice models include nudging (Lindsay and Zhang, 2006; Tietsche et al., 2012), optimal interpolation techniques (Zhang et al., 2003; Dulière and Fichefet, 2007; Stark et al., 2008), and ensemble Kalman filtering (Lisæter et al., 2003, 2007; Mathiot et al., 2012). Two salient and advantageous characteristics of the ensemble Kalman filter (EnKF) are its intrinsic multivariate nature and its appropriateness for nonlinear models. Multivariate data assimilation means that all elements of the state vector are subject to analysis; thus the assimilation of only one variable (e.g., sea ice concentration) also impacts non assimilated variables (e.g., sea ice thickness). On the other hand, the EnKF is particularly well suited for strongly nonlinear models (e.g., sea ice models) because the model error covariance matrix is derived from multiple ensemble forecasts (thus preserving the nonlinear nature of the model) and not defined a priori (Evensen, 2003; Lisæter et al., 2007). Still, the EnKF relies on several hypotheses, including the gaussianity of the model forecast and observation covariance matrices, that are obviously not met in the particular case of sea ice. For example, sea ice concentration is bounded by 0 and 1 , and these two extreme values are the most common modes of the distribution.

The way the EnKF is implemented in the ocean-sea ice NEMOLIM2 is fully described in Mathiot et al. (2012). In short, the assimilation works in a two-step sequence: forecast and analysis. First, an ensemble of 25 members is run forward in time until observations are available (here, sea ice concentration, see next paragraph). A gaussian perturbation in the wind forcing field 
guarantees that the 25 members sample a reasonable portion of the model uncertainty space. Second, model error statistics are derived from this 25-member sample. Together with observational errors statistics, they are used to weight the model and observational estimates of the system state. At this analysis step, observations are treated as random variables in order to maintain a sufficiently large variance in the updated ensemble (Burgers et al., 1998). Because of the limited size of our ensemble, spurious correlations may exist between distant and non-physically related variables. Our version of the EnKF therefore includes a localized analysis (Sakov and Bertino, 2010) that simply ignores those undesired correlations when the distance between two variables exceeds $800 \mathrm{~km}$. The ocean-sea ice state vector consists in all prognostic variables of the ocean and sea ice model, except for sea ice temperature and heat content that are simply forecasted from one time step to the next (Mathiot et al., 2012). Note finally that, by definition, the update of non-assimilated variables (e.g., sea surface salinity) is based on their statistical relationships with assimilated variables (sea ice concentration). Therefore, the ocean-sea ice system is not necessarily conserving oceanic salt. Still, a weak restoring to climatological sea surface salinity is prescribed, see Section 2.1.

We assimilate the latest version of the global reprocessed sea ice concentration data from the European Meteorological Satellite Agency (EUMETSAT) Ocean and Sea Ice Satellite Application Facility (OSISAF) (Eastwood et al., 2011). Sea ice concentration is not directly observed from space. Measurements of brightness temperatures (here obtained from the Scanning Multichannel Microwave Radiometer and Special Sensor Microwave/Imager instruments) are used along with an appropriate algorithm (here, a combination of the Bootstrap and Bristol algorithms) to provide estimates of the sea ice concentration. The final product is provided on a $12.5 \mathrm{~km}$ resolution grid at an almost daily frequency from November 1978 to October 2009, and then spatially interpolated with a bilinear scheme on the model grid. Time-varying uncertainties on the ice concentration at each grid cell are provided, making the OSISAF product a unique dataset for assimilation purposes.

\subsection{Experimental setup}

The run "ASSIM" is defined as follows. NEMO-LIM2 is initialized in January 1960 with the ocean temperature and salinity fields of Levitus (1998). A uniform sea ice (snow) thickness of $1 \mathrm{~m}(0.1 \mathrm{~m})$ is prescribed wherever the sea surface temperature lies below $0{ }^{\circ} \mathrm{C}$ in the Southern Hemisphere, and the ice concentration is set to $90 \%$ at these locations. Sea ice temperature is initially set at the seawater freezing point. The assimilation is active whenever observations of sea ice concentration are available, i.e. from November 1978 onwards. The first 14 months of the data assimilation are excluded from the analysis as to let the ocean-sea ice system adjust to the constraints imposed by the EnKF. We therefore focus here on the 1980-2008 time period for our analyses.

For ASSIM, the mean of all analyzed 25 members is presented and is considered as representative of the ensemble. This will be the run used for the reconstruction of sea ice thickness and volume. Another run is also presented: "FREE". As the name suggests, we turned off the assimilation procedure in this run (one run is conducted without wind perturbation).

\section{Effect of assimilation on model biases}

We show in this section that the run with data assimilation of sea ice concentration (ASSIM) displays a much better seasonality and interannual variability than FREE in the Southern Hemisphere. This demonstrates the efficiency of the EnKF inclusion in NEMOLIM2. Additionally, due to the multivariate nature of the filter, the biases in sea ice thickness (and as a consequence sea ice volume) are also partly corrected in ASSIM with respect to FREE. This provides a good basis for addressing the interannual changes in Antarctic sea ice volume and thickness using ASSIM.

\subsection{Sea ice concentration and extent}

Before discussing the interannual variability of ASSIM, we propose to examine the characteristics of this run for the seasonal means. This provides views on how the assimilation acts on the mean-state related biases of FREE. Hereafter, we use the (Cavalieri et al., 1996) dataset of sea ice concentration to assess the skill of ASSIM and FREE in the Southern Ocean. This dataset is different from that used for the assimilation (Eastwood et al., 2011). Both products are not fully independent since they emanate from the same satellite sensors. However, the algorithms used for deriving sea ice concentration are different. The former uses the NASA-team algorithm and the latter a combination of the Bristol and Bootstrap algorithms. In addition, we do not interpolate the Cavalieri et al. sea ice concentration data on the model grid but use the original grid of the product.

Year-around, ASSIM (red lines on Fig. 1) displays a much better agreement with observations (black) than FREE (blue). The mean sea ice extent lies, with a few exceptions, always in the $\pm 2 \sigma$ envelope around observations for every chosen sub-region of the domain. Without data assimilation (FREE), NEMO-LIM2 tends to simulate too extensive a sea ice cover in winter because of the overestimation in the eastern sectors (Indian Ocean and Pacific Ocean). These biases are corrected in ASSIM. In summer, FREE features a reasonably correct sea ice extent, although it displays icefree conditions in the Pacific Ocean area. Again, the summer mean sea ice extent conditions are better represented with ASSIM. Regarding the mean sea ice extent, the results depicted in Fig. 1 confirm that the EnKF is an efficient tool for correcting the FREE biases due to the ocean-sea ice model itself (Timmerman et al., $2004,2005)$ or to the presence of biases in the NCEP/NCAR atmospheric forcing (Bromwich et al., 2007; Vancoppenolle et al., 2011).

On interannual time scales, ASSIM also outperforms FREE (Table 1A and B; Fig. 2(a)-(c)). In its FREE configuration, NEMOLIM2 fails at reproducing the significant downward trend in sea ice extent observed in the Amundsen-Bellingshausen Seas over the previous decades. FREE also yields a negative trend in sea ice concentration and extent in the Weddell Sea sector, while remote sensed observations report a slight increase in this area. After assimilation of sea ice concentration (ASSIM), these shortcomings are largely suppressed. Visual comparison between panels a and c of Fig. 2 suggests a much better agreement than between panels $\mathrm{a}$ and $\mathrm{b}$. This is confirmed by the correlation coefficients (Table 1B) scores that are systematically higher for ASSIM.

The statistics of Table 1 reflect why it is important to break down the analysis of the Southern Ocean sea ice in sectors. Just as the observed trends in sea ice concentration/extent exhibit opposite signs around the Antarctic continent (Parkinson and Cavalieri, 2012; Comiso and Nishio, 2008), the FREE and ASSIM performance (i.e., agreement with observations) varies greatly from one sector to another. Furthermore, the overall performance in the Southern Ocean is not a simple average of the performance at regional levels. For instance, the correlations between observed and modeled anomalies in hemispheric sea ice extent are lower than in each of the five sub-regions. Note that all these results are similar if sea ice area (not shown here) is used instead of sea ice extent.

\subsection{Sea ice thickness}

By definition of multivariate data assimilation, any variable of the state vector is updated as long as it covariates with the 

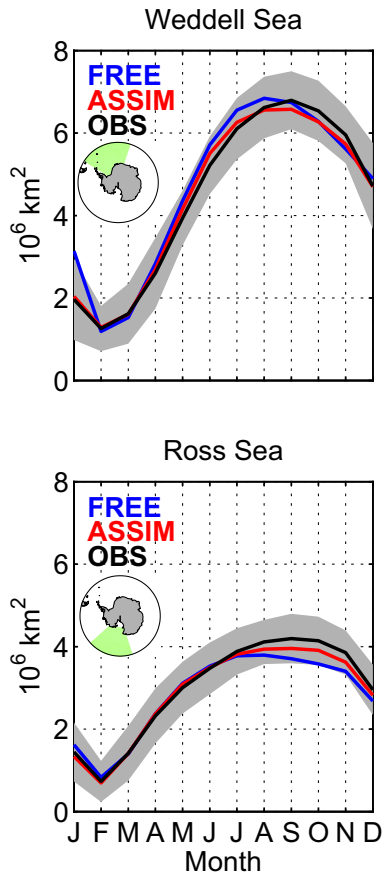

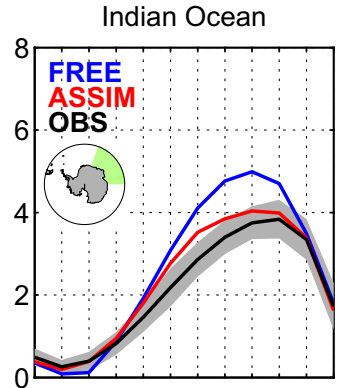

Amund.-Bell. Seas

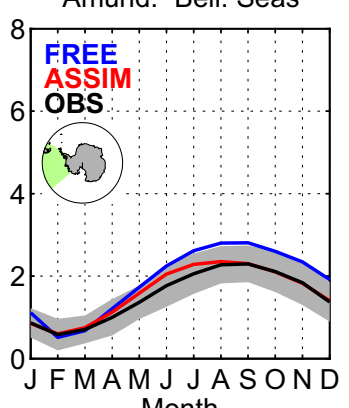

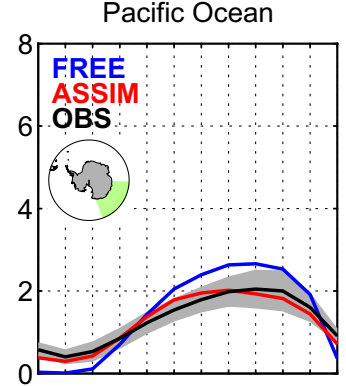

Southern Ocean

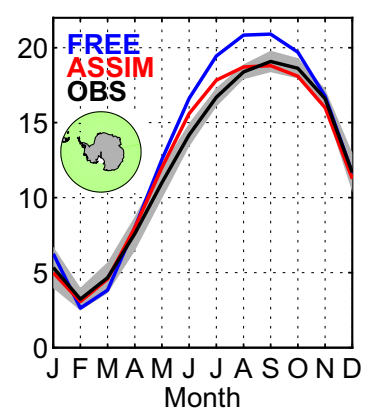

Fig. 1. Mean seasonal cycle of sea ice extent (1980-2008) in various sectors (insets) of the Southern Ocean (Weddell Sea, Indian Ocean, Pacific Ocean, Ross Sea, AmundsenBellingshausen Seas) and the whole Southern Ocean, from observations (black), free run (blue) and assimilated run (red). Sea ice extent is defined as the total area of oceanic grid cells comprising at least $15 \%$ of ice. Note the different $y$-axis scale for the lower right panel. The grey shaded areas are the $\pm 2 \sigma$ envelopes of the observed monthly sea ice extent anomalies over the corresponding period from observations (Cavalieri et al., 1996). (For interpretation of the references to color in this figure legend, the reader is referred to the web version of this article.)

Table 1

A. 1980-2008 trends of monthly anomalies of sea ice extent in different sectors of the Southern Ocean (the same as those of Fig. 1). For observations (Cavalieri et al., 1996), the $\pm 2 \sigma$ estimate on the trend is also provided. The modeled trends are in bold when they lie in the confidence interval of the observations. B. Correlations between observed and simulated 1980-2008 monthly anomalies of sea ice extent in the corresponding sectors. C. Mean absolute difference of sea ice thickness with respect to the ASPeCt (Worby et al., 2008) dataset between 1980 and 2008. In the table, FREE (ASSIM) refers to the run without (with) assimilation of ice concentration.

\begin{tabular}{|c|c|c|c|c|c|c|c|}
\hline \multirow[t]{2}{*}{ Sector $\downarrow$} & \multicolumn{3}{|c|}{ A. Trends sea ice extent \%/decade } & \multicolumn{2}{|c|}{ B. Correlation of monthly anomalies } & \multicolumn{2}{|c|}{ C. Mean thickness bias $(\mathrm{cm})$} \\
\hline & OBS & FREE & ASSIM & FREE & ASSIM & FREE & ASSIM \\
\hline Weddell Sea & $1.60 \pm 2.69$ & -2.18 & 2.15 & 0.57 & 0.96 & 29 & 23 \\
\hline Ind. Ocean & $1.93 \pm 2.59$ & 4.84 & 3.22 & 0.57 & 0.87 & 21 & 17 \\
\hline Pacific Ocean & $1.02 \pm 3.96$ & 5.71 & 3.84 & 0.62 & 0.88 & 38 & 30 \\
\hline Ross Sea & $4.46 \pm 3.10$ & 7.01 & 5.66 & 0.75 & 0.96 & 35 & 31 \\
\hline Amund.-Bel. Seas & $-5.41 \pm 4.35$ & 1.09 & -3.01 & 0.67 & 0.93 & 26 & 17 \\
\hline Southern Ocean & $1.44 \pm 0.82$ & 2.41 & 2.66 & 0.53 & 0.81 & 30 & 24 \\
\hline
\end{tabular}

assimilated variable(s). In previous works, Lisæter et al. (2003), Lindsay and Zhang (2006), Stark et al. (2008) and Mathiot et al. (2012) showed indeed that in the Arctic, the assimilation of one or two key sea ice variables (concentration and/or drift) leads to improvements of the simulated sea ice thickness. This very valuable property is still at the heart of ongoing reanalyses of the total Arctic sea ice volume (e.g., Schweiger et al., 2011).

In agreement with these results derived for the Arctic, the assimilation of ice concentration has positive impacts on the Southern Ocean ice thickness as well (Table 1C). The numbers are obtained by averaging, over all months between 1980 and 2008 and all grid cells falling in the corresponding sectors, the absolute difference ("bias") between (1) the available ASPeCt (Worby et al., 2008) sea ice thickness estimates interpolated on the model grid and (2) the model sea ice thickness at the corresponding locations. Another metric could have been to compare the mean sea ice thickness from the ASPeCt dataset over the sectors with the average modeled thickness (as in, e.g., Timmerman et al., 2004), but this would then have possibly hidden a compen- sation of errors. In this sense, our metric is more restrictive but also more subject to observational errors. Note that a more commonly used but less physical metric, the Root Mean Squared Error, gives similar results (not shown here).

After assimilation, the biases on sea ice thickness are reduced by $\sim 20 \%$ on average, with the greatest corrections in the Amundsen-Bellingshausen Seas. Note that this is precisely where NEMO-LIM2, in its FREE configuration, shows trends in sea ice extent and concentration with the wrong sign compared to observations (Fig. 2(b) and Table 1A). Still, ASSIM does not fully eliminate the thickness biases of FREE (Table 1C). We put forward three possible reasons:

- The analysis given by the EnKF is a linear combination of observational and model states but accounts for their respective error covariance matrices. It is therefore impossible to fully remove the FREE biases as long as assimilated observations - here, sea ice concentrations - are subject to uncertainties (and this is well the case). 


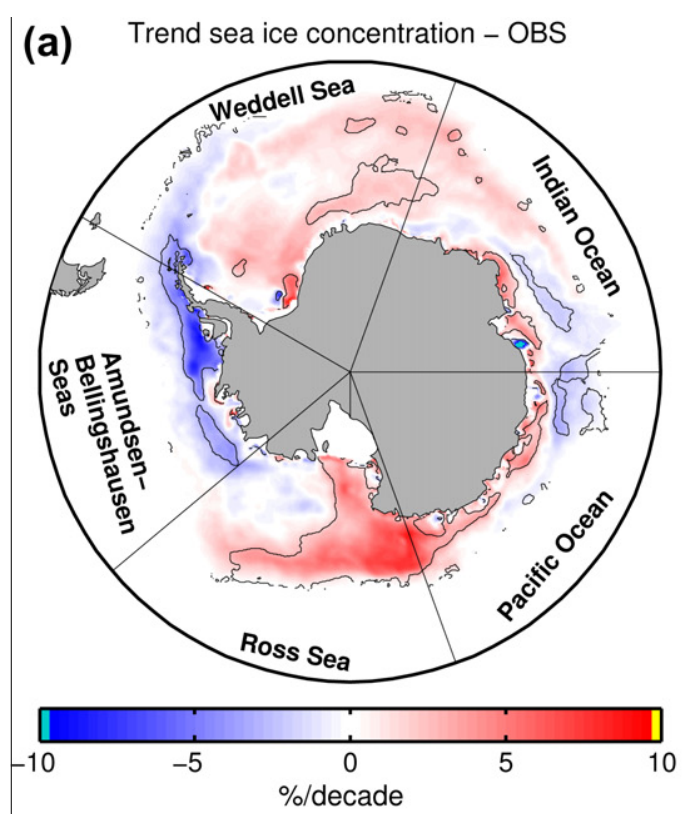

(c) Trend sea ice concentration - ASSIM

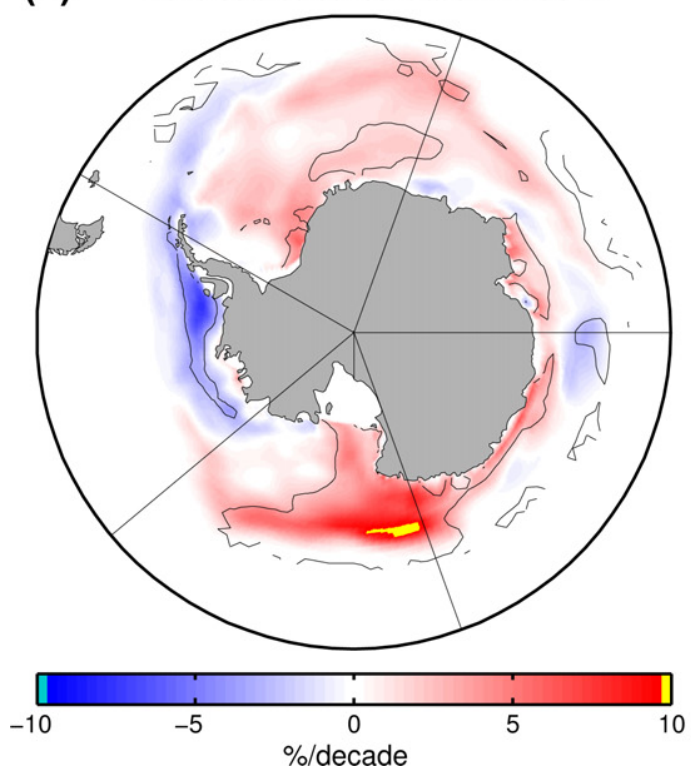

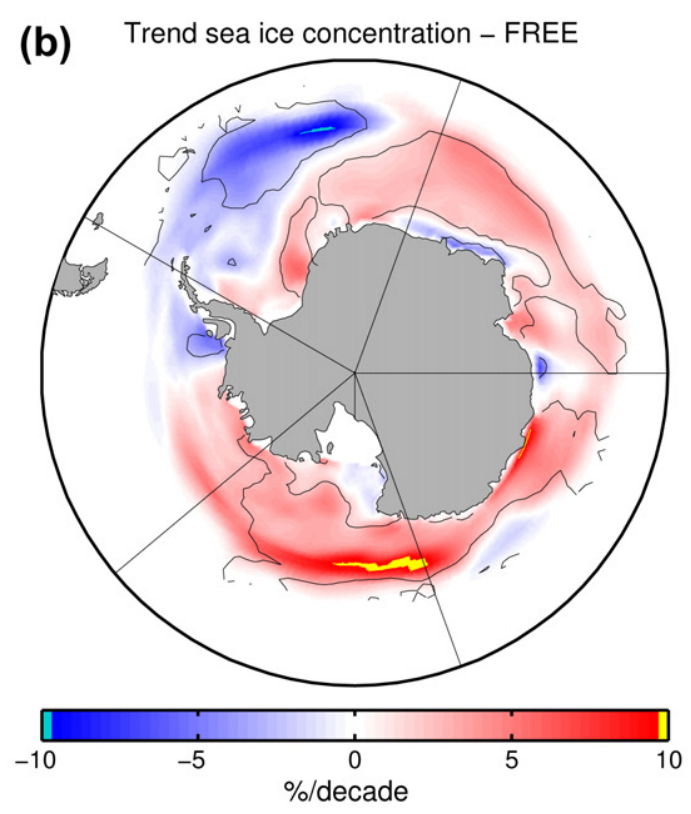

(d) Trend sea ice thickness - ASSIM

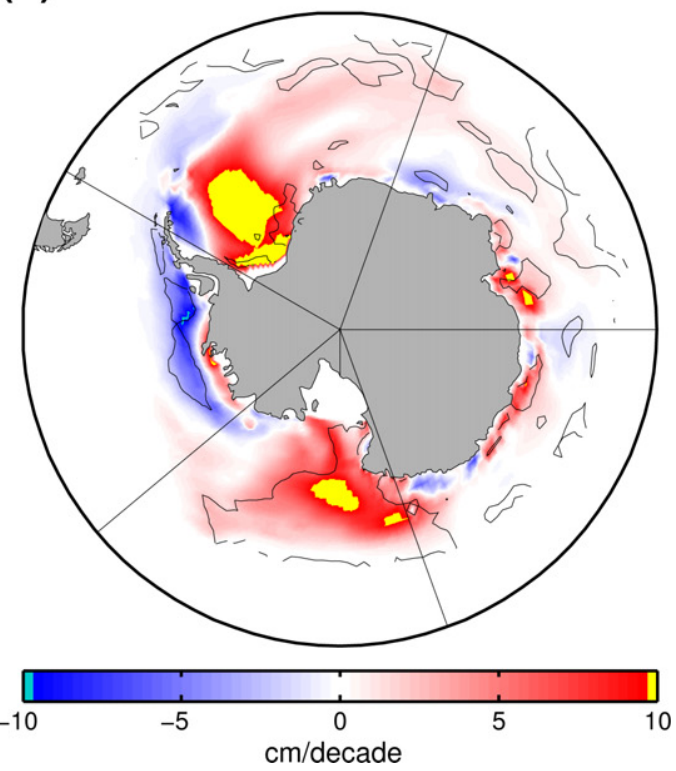

Fig. 2. (a,b,c) 1980-2008 trends in Antarctic sea ice concentration as observed (a: Cavalieri et al., 1996), simulated by the model without data assimilation (b: FREE) and after data assimilation of sea ice concentration (c: ASSIM); (d) 1980-2008 trends in sea ice thickness as reconstructed after data assimilation (ASSIM). For all four panels, the trends are derived from the monthly anomalies with respect to the 1980-2008 mean seasonal cycle, and are statistically significantly different from zero ( $p<0.05$ ) in regions enclosed by the black contour lines.

- Sea ice thickness is not the assimilated variable and is therefore updated based only on its relationship to concentration in the model.

- The ASPeCt dataset itself contains errors (Worby et al., 2008). Even under a "perfect" model setup, the metrics of Table $1 \mathrm{C}$ would not go to zero.

We argue however that the improvements reported in Fig. 2 and Table 1 form a fair basis to propose a reconstruction of the Antarctic sea ice volume and thickness with ASSIM.

\section{Changes in Antarctic sea ice thickness and volume}

In this section, we give two views on the sea ice thickness and volume changes in the Southern Ocean. Spatial trends in sea ice thickness, on the one hand, provide a global view on sea ice thickness changes since 1980 and suggest that ice thickness and concentration are well coupled on time scales beyond the season. On the other hand, time series of monthly anomalies of sea ice volume in the various sectors of the Southern Ocean allow to diagnose variability on a wide range of frequencies. For the whole Southern Ocean, a statistically significant increase in sea ice volume is found.

\subsection{Spatial trends: thickness}

The 1980-2008 trends in sea ice thickness from ASSIM are shown in Fig. 2(d). The regions of statistical significance of these trends are enclosed by the black line contours. A strong dipole signal is visible: thinning in the Amundsen-Bellingshausen Seas, thickening in the Ross Sea. A visual comparison with the trends 
in concentration (Fig. 2(c)) indicates that, at least in these two sectors, changes in sea ice concentration and thickness are coupled. A strong thickening is diagnosed in the Weddell Sea but is not statistically significant as the interannual variability of ice thickness is very large in this sector. The opposite trends in sea ice thickness in the Amundsen-Bellingshausen and Ross Seas are the result of thermodynamic and/or dynamic processes. We review in the next paragraph the possible role of atmospheric forcing on these changes.

The dipolar structure of the trends in sea ice thickness (Fig. 2(d)) can be interpreted in light of the Southern Annular Mode (SAM) and El Niño-Southern Oscillation (ENSO) variability. The SAM (e.g., Carleton, 2003) is a dominant feature of the atmospheric variability in the extratropical Southern Hemisphere. It is classically invoked to interpret the recently observed non-annular changes in sea ice concentration in the Southern Ocean (Lefebvre et al., 2004; Liu et al., 2004; Thompson and Solomon, 2002). Yet, it explains only a limited fraction of the internal variability of sea ice (Lefebvre and Goosse, 2005). When SAM ${ }^{1}$ shifts towards its positive polarity, as is the case since 1979 , the westerlies tend to strengthen. The consequences are (1) an increased wind-induced ice transport equatorwards, and (2) an overall cooling over the Antarctic continent due to increased isolation, with notable exceptions around the Antarctic Peninsula (Thompson and Solomon, 2002) and in Central West Antarctica (Bromwich et al., 2012). In fact, an anomalous low pressure system develops over the Amundsen-Bellingshausen Seas during high-index SAM years (Lefebvre and Goosse, 2005 and their Fig. 1) deflecting the westerlies southeastwards in the Amundsen-Bellingshausen Seas and around the Antarctic Peninsula. The advection of warm air may have produced a thermodynamic thinning of the ice (Fig. 2(d)). In the Ross Sea, increased sea ice transport may have caused an increased horizontal divergence of the sea ice pack, favouring the creation of new ice and exporting it equatorwards. Combined with enhanced southerly cold winds in this sector (Holland and Kwok, 2012), the net result is a thickening of the sea ice pack offshore in this sector (Fig. 2(d)). A slight shift of ENSO towards its negative phase provides qualititatively similar regional changes in the sea ice cover (Liu et al., 2004). Like SAM, the trends explained by ENSO variability are however much smaller than observed trends.

Sea ice thickness trends in the Weddell Sea sector peak up to $10-15 \mathrm{~cm} /$ decade, but are rarely significant. Sea ice in this region is known to be thicker than in the rest of the Southern Ocean (Worby et al., 2008), implying that it is also likely to exhibit larger interannual fluctuations than anywhere else. Close to the ice edge, small but significant thinning (thickening) is found in the western (eastern) part of the Weddell Sea sector, and may be a simple consequence of the ice edge retreat (advance) evidenced by Stammerjohn et al. (2012). The ultimate reason for these changes in ice edge location possibly lies in the changes in winds and the associated changes in ice transport. Since the 1990s, winds in the western Weddell Sea sector have blown northwards with less intensity (Holland and Kwok, 2012), hampering and slowering the usual ice export northwards. On the other hand, enhanced southerly winds in the eastern Weddell Sea sector increased ice export with direct impacts on the ice edge location. In the Pacific and Indian Ocean sectors, the distribution of sea ice thickness trends is more patchy with many small regions of positive and negative trends. On the sector scale, these contributions cancel out so that the net changes in ice volume are not statistically different from zero (see next section). Holland and Kwok (2012) argue that thermodynamical processes are the primary cause for ice concentration changes in eastern Antarctic sea ice. In view of the presence

\footnotetext{
${ }^{1}$ The SAM index data is publicly available at http://www.jisao.washington.edu aao/slp/. The trend of the SAM index over $1979-2010$ is 0.23 /decade.
}

of positive and negative trends in surface air temperature in this region (Shu et al., 2012), the same thermodynamical processes can explain the locally positive and negative ice thickness trends in both Pacific and Indian Ocean sectors.

\subsection{Integrated anomalies: volume}

Fig. 3 depicts the anomalies (monthly time series minus the mean seasonal cycle) of the Antarctic sea ice volume in the different sectors from ASSIM. This simulation displays an overall, statistically significant increase in Antarctic sea ice volume over 19802008 of $5.58 \pm 5.31 \%$ per decade (Fig. 3 and Table 2). As for the trend in sea ice extent, this increase results from positive (e.g., Ross Sea, significant increase) and negative (Amundsen-Bellingshausen Seas, not significant decrease) contributions. The changes in sea ice volume of the whole Southern Ocean sea ice volume are primarily driven by the changes in the Weddell Sea (correlation of anomalies in this sector with overall anomalies: 0.87) and, to a lesser extent, by the changes in the Ross Sea (correlation: 0.52) and Pacific Ocean (0.50) sectors.

The trends in sea ice volume (Table 2 ) are consistent with the spatial trends in sea ice thickness displayed in Fig. 2(d). The time series of sea ice volume anomalies provide, however, an additional information about the nature of the signal. The time series exhibit strong variability from interannual to decadal time scales in all sectors (Fig. 3). The sea ice itself has a very limited memory in the Southern Ocean, because it is mostly seasonal with exceptions in some portions of the Weddell Sea. Our results underline therefore that long-term fluctuations in the sea ice volume are mainly caused by the atmosphere and ocean variability. Such fluctuations in ice thickness and volume have also been identified in previous model-only studies (Zhang, 2007; Fichefet et al., 2003a). They may be due to a response to the forcing and in particular to ozone changes (e.g., Turner et al., 2009; Bitz and Polvani, 2012), to remote changes in the tropical Pacific (e.g., Ding et al., 2011, 2012), to the presence of an Antarctic Circumpolar Coastal wave (Beckmann and Timmermann, 2001) or a consequence of modifications in the stratification in the ocean (Zhang, 2007; Goosse et al., 2009).

Anomalies in sea ice volume co-vary well with anomalies in sea ice extent. In the Weddell Sea, Indian Ocean, Pacific Ocean, Ross Sea and Amundsen-Bellingshausen Seas sectors, the correlations amount to $0.66,0.71,0.73,0.66$ and 0.68 respectively. The overall Antarctic sea ice extent and volume anomalies correlate at 0.55 (lower than all five previously listed correlations). This is again a hint that the analysis should first be carried out sector per sector.

\section{Conclusions and summary}

We present in this work a multi-decadal reconstruction of the Antarctic thickness and volume sea ice changes (Figs. 2(d) and 3 and Table 2). A (multivariate) ensemble Kalman filter scheme is used to assimilate real sea ice concentration data into the stateof-the art ocean-sea ice model NEMO-LIM2. Compared to modelonly studies (e.g., Fichefet et al., 2003a; Zhang, 2007), this approach has the advantage to account for the model and atmospheric forcing biases (Section 3). Compared to observational-only studies (e.g., Worby et al., 2008; DeLiberty et al., 2011; Yi et al., 2011), it has the advantage to provide a global, multi-decadal and regularly sampled spatio-temporal thickness field (Fig. 2(d)).

Our results suggest (1) that sea ice volume and thickness covary well with extent and concentration at the multi-decadal time scale in the Southern Ocean (compare for example Fig. 2(c) with (d)). (2) Sea ice volume displays marked fluctuations up to the decadal time scale, similarly to previous studies using no data assimilation (Fichefet et al., 2003b; Zhang, 2007). (3) An overall 

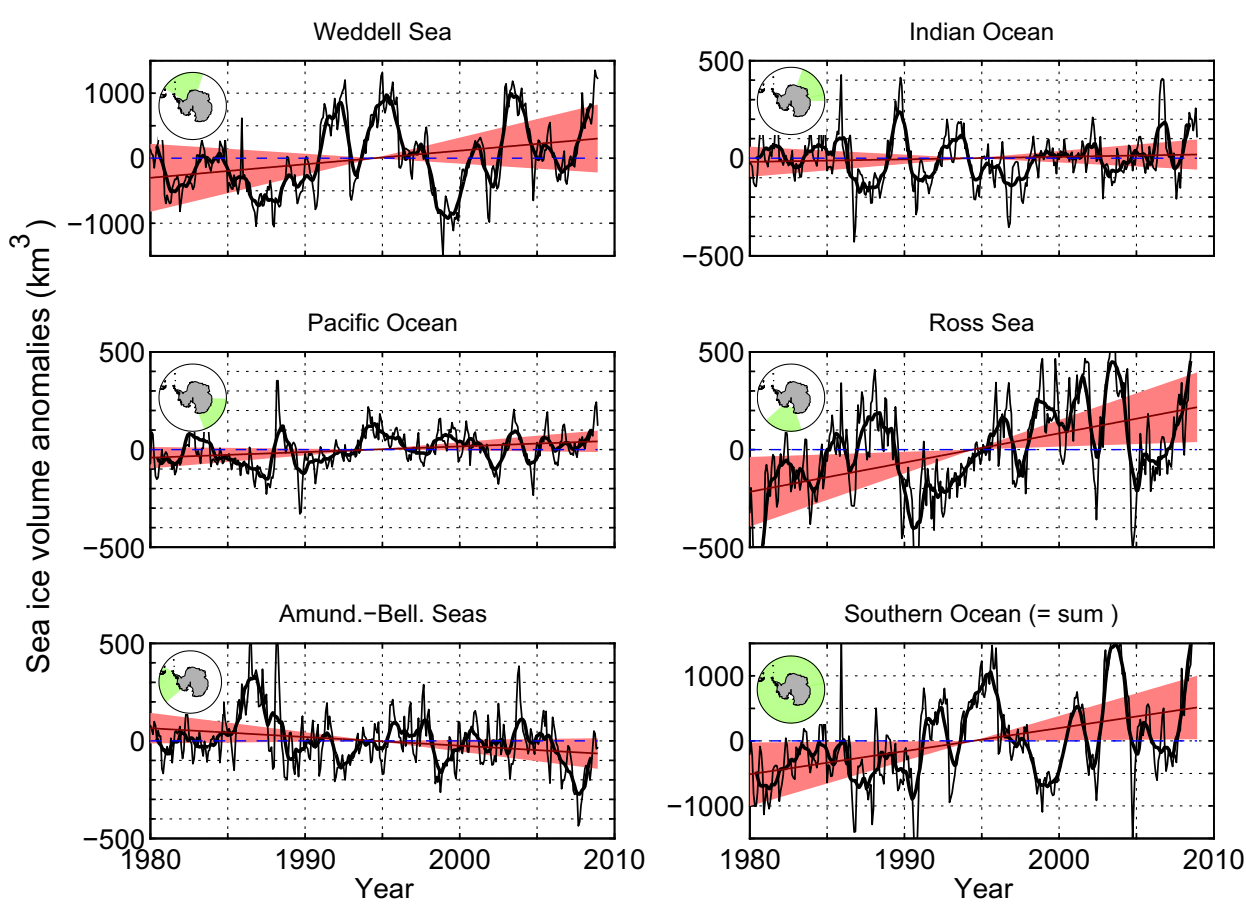

Fig. 3. Variability of Southern Ocean sea ice volume from the run with data assimilation of sea ice concentration (ASSIM). The thin black lines show the monthly anomalies of sea ice volume, the bold black lines are a 11-month smoothing of these anomalies. The red line is the linear fit of the unsmoothed anomalies, and the red shading reproduces the $\pm 2 \sigma$ estimate of the slope of this linear fit. The values of the trends in sea ice volume can be found in Table 2 . The blue dashed line is the zero trend line. Note the different $y$-axes in the Weddell Sea and Southern Ocean panels. (For interpretation of the references to color in this figure legend, the reader is referred to the web version of this article.)

Table 2

1980-2008 Trends of sea ice volume in different sectors as simulated by ASSIM \pm 2 standard deviations of the estimator for slope of the linear fit.

\begin{tabular}{lll}
\hline Sector $\downarrow$ & \multicolumn{2}{l}{ Trend sea ice volume } \\
\cline { 2 - 3 } & $\mathrm{km}^{3} /$ decade & \%/decade \\
\hline Weddell Sea & $208.6 \pm 361.6$ & $6.76 \pm 11.73$ \\
Indian Ocean & $13.0 \pm 53.5$ & $1.94 \pm 7.97$ \\
Pacific Ocean & $28.9 \pm 38.0$ & $7.25 \pm 9.54$ \\
Ross Sea & $149.9 \pm 123.6$ & $10.23 \pm 8.43$ \\
Amund.-Bel. Seas & $-44.8 \pm 54.1$ & $-5.94 \pm 7.18$ \\
Southern Ocean & $355.5 \pm 338.0$ & $5.58 \pm 5.31$ \\
\hline
\end{tabular}

statistically significant increase in Antarctic sea ice volume is found ( $355 \pm 338 \mathrm{~km}^{3} /$ decade), but (4) we insist on the need to break down regionally the analysis of Antarctic sea ice variability in order to make its understanding easier. Locally, sea ice thickness trends can amount to $10-15 \mathrm{~cm} /$ decade in the Ross Sea and Weddell Sea sectors, and to $-10 \mathrm{~cm} /$ decade in the Amundsen-Bellingshausen Seas. The variations of sea ice volume in the Weddell Sea Sector (where the ice is also the thickest) explain a reasonable part of the total Antarctic sea ice volume changes but the contributions from other sectors cannot be neglected.

To the best of our knowledge, this is the first time that a reconstruction of the Antarctic sea ice volume and thickness changes over the past few decades is presented using data assimilation. We are aware of several shortcomings regarding the experimental setup, for example the questionable quality of the NCEP/NCAR reanalyses used to force the model and the absence of proper correction on the freshwater budget after the assimilation time step. Future work will be devoted to tackle these weaknesses, as well as to implement the assimilation scheme in the more sophisticated ocean-sea ice model NEMO-LIM3 (Vancoppenolle et al., 2009). Compared to the model used in this study, NEMO-LIM3 simulates explicitly the vertical profile of salinity, resolves the distribution of ice thickness into 5 ice categories and ice dynamics is treated with elastic viscous-plastic rheology. The assimilation of other potentially important variables, including sea surface temperature and sea ice drift, will also be considered. We view the present study as a very first attempt to reconstruct the sea ice thickness and volume variations in the Southern Hemisphere using data assimilation. Nonetheless, our reconstruction may be a valuable and possible useful source of information for polar climate scientists, because of the demonstrated positive impacts of the data assimilation system on the simulated global sea ice cover. Note that the full reconstruction is freely available upon request to the authors.

\section{Acknowledgments}

F. Massonnet is a F.R.S-FNRS Research Fellow. H. Goosse is a F.R.S.-FNRS Senior Research Associate. This work was partly funded by the European Commissions 7th Framework Programme, under Grant Agreement number 226520, COMBINE project (Comprehensive Modelling of the Earth System for Better Climate Prediction and Projection). It was also partly supported by the Belgian Science Federal Policy Office (BELSPO). The global sea ice concentration reprocessed dataset was provided by the Ocean and Sea Ice Satellite Application Facilities (OSISAF). The Upward Looking Sonar ice draft profiles were provided by the National Snow and Ice Data Center (NSIDC, www.nsidc.org). The ship-based sea ice and snow thickness data were provided by the SCAR Antarctic Sea Ice Processes and Climate (ASPeCt) program (www.aspect.aq). Computational ressources have been provided by the supercomputing facilities of the Université catholique de Louvain (CISM/UCL) and the Consortium des Equipements de Calcul Intensif en Fédération Wallonie Bruxelles (CECI) funded by the F.R.S.-FNRS. 


\section{Appendix A. Supplementary data}

Supplementary data associated with this article can be found, in the online version, at http://dx.doi.org/10.1016/j.ocemod.2013. 01.003 .

\section{References}

Arzel, O., Fichefet, T., Goosse, H., 2006. Sea ice evolution over the 20th and 21st centuries as simulated by current AOGCMs. Ocean Modell. 12, 401-415.

Baumgartner, A., Reichel, E., 1976. The world water balance mean annual global, continental and maritime precipitation, evaporation and run-off. Agric. Water Manage. 1 (1), 100-101 <http://ideas.repec.org/a/eee/agiwat/v1y1976i1p100101.html>.

Beckmann, A., Döscher, R., 1997. A method for improved representation of dense water spreading over topography in geopotential-coordinate models. J. Phys. Oceanogr. 27 (4), 581-591 <http://dx.doi.org/10.1175/1520-0485(1997)027 $<0581$ :AMFIRO>2.0.CO;2>.

Beckmann, A., Timmermann, R., 2001. Circumpolar influences on the weddell sea: indication of an Antarctic circumpolar coastal wave. J. Climate 14 (17), 37853792 0442(2001)014<3785:CIOTWS>2.0.CO;2>

Berliand, M.E., Strokina, T.G., 1980. Global Distribution of the Total Amount of Clouds, Hydrometeorological, Leningrad, 71 (in Russian).

Bitz, C.M., Polvani, L.M., 2012. Antarctic climate response to stratospheric ozone depletion in a fine resolution ocean climate model. Geophys. Res. Lett. 39 (20) L20705 <http://dx.doi.org/10.1029/2012GL053393>.

Bromwich, D.H., Fogt, R.L., Hodges, K.I., Walsh, J.E., 2007. A tropospheric assessment of the ERA-40, NCEP, and JRA-25 global reanalyses in the polar regions. J. Geophys. Res. 112, D10111.

Bromwich, D.H., Nicolas, J.P., Monaghan, A.J., Lazzara, M.A., Keller, L.M., Weidner, G.A., Wilson, A.B., 2012. Central West Antarctica among the most rapidly warming regions on Earth. Nature Geosci. Advance Online Publication: <http:// dx.doi.org/10.1038/ngeo1671>.

Burgers, G., Jan van Leeuwen, P., Evensen, G., 1998. Analysis scheme in the ensemble Kalman filter. Mon. Weather Rev. 126 (6), 1719-1724 <http://dx.doi.org/ 10.1175/1520-0493(1998)1261<719:ASITEK>2.0.CO;2>.

Carleton, A.M., 2003. Atmospheric teleconnections involving the Southern Ocean. J. Geophys. Res. 108 (C4), 8080 <http://dx.doi.org/10.1029/2000JC000379>.

Cavalieri, D., Parkinson, C., Gloersen, P., 1979-2010. (updated yearly), H.J.Z., 1996 Sea Ice Concentrations from Nimbus-7 SMMR and DMSP SSM/I-SSMIS Passive Microwave Data.

Cavalieri, D.J., Parkinson, C.L., 2012. Arctic sea ice variability and trends, 1979-2010 Cryos. Discuss. 6 (2), 957-979 <http://www.the-cryosphere-discuss.net/6/957/ 2012/>

Cavalieri, D.J., Parkinson, C.L., Vinnikov, K.Y., 2003. 30-Year satellite record reveals contrasting Arctic and Antarctic decadal sea ice variability. Geophys. Res. Lett. 18.

Comiso, J.C., Nishio, F., 2008. Trends in the sea ice cover using enhanced and compatible AMSR-E, SSM/I and SMMR data. J. Geophys. Res., 113.

Connolley, W.M., Bracegirdle, T.J., 2007. An Antarctic assessment of IPCC AR4 coupled models. Geophys. Res. Lett. 34, L22505.

DeLiberty, T.L., Geiger, C.A., Ackley, S.F., Worby, A.P., Van Woert, M.L., 2011. Estimating the annual cycle of sea-ice thickness and volume in the Ross Sea. Deep Sea Res. II 58, 1250-1260.

Ding, Q., Steig, E.J., Battisti, D.S., Kuttel, M., 2011. Winter warming in West Antarctica caused by central tropical Pacific warming. Nature Geosci. 4 (6), 398 $403<$ http://dx.doi.org/10.1038/ngeo1129>.

Ding, Q., Steig, E.J., Battisti, D.S., Wallace, J.M., 2012. Influence of the tropics on the Southern Annular Mode. J. Climate 25 (18), 6330-6348 <http://dx.doi.org/ 10.1175/JCLI-D-11-00523.1>.

Dulière, V., Fichefet, T., 2007. On the assimilation of ice velocity and concentration data into large-scale sea ice models. Ocean Sci. 3 (2), 321-335 <http:/| www.ocean-sci.net/3/321/2007/>

Eastwood, S., Larsen, K.R., Lavergne, T., Nielsen, E., Tonboe, R., 2011. Global sea ice concentration reprocessing - product user manual. Tech. Rep., OSISAF.

Evensen, G., 2003. The ensemble Kalman filter: theoretical formulation and practical implementation. Ocean Dyn. 53, 343-367.

Fichefet, T., Goosse, H., Morales Maqueda, M.A., 2003a. A hindcast simulation of Arctic and Antarctic sea ice variability, 1955-2001. Polar Res. 22, 91-98.

Fichefet, T., Morales Maqueda, M.A., 1997. Sensitivity of a global sea ice model to the treatment of ice thermodynamics and dynamics. J. Geophys. Res. 102 12609-12646.

Fichefet, T., Tartinville, B., Goosse, H., 2003b. Antarctic sea ice variability during 1958-1999: a simulation with a global ice-ocean model. J. Geophys. Res. 108 (C3), 3102.

Goosse, H., 1997. Modelling the large-scale behaviour of the coupled ocean-sea-ice system. Ph.D. Thesis, Université Catholique de Louvain.

Goosse, H., Fichefet, T., 1999. Importance of ice-ocean interactions for the global ocean circulation: a model study. J. Geophys. Res. 104, 23337-23355.

Goosse, H., Lefebvre, W., de Montety, A., Crespin, E., Orsi, A., 2009. Consistent past half-century trends in the atmosphere, the sea ice and the ocean at high Southern Latitudes. Climate Dyn. 33, 999-1016.
GRDC, 2000. Observed historical discharge data from major rivers for climate model validation. Tech. Rep., Max Planck Institute. <https://www.mpimet.mpg.de/ fileadmin/publikationen/Reports/maxscirep307.pdf>.

Hibler, W.D., 1979. A dynamic thermodynamic sea ice model. J. Phys. Oceanogr. 9, 815-846.

Holland, M., Raphael, M.N., 2006. Twentieth century simulation of the Southern Hemisphere climate in coupled models. Part II: Sea ice conditions and variability. Climate Dyn. 26, 229-245.

Holland, P.R., Kwok, R., 2012. Wind-driven trends in Antarctic sea-ice drift. Nature Geosci. Advance Online Publication: <http://dx.doi.org/10.1038/ngeo1627>

Kalnay, E., Kanamitsu, M., Kistler, R., Collins, W., Deaven, D., Gandin, L., Iredell, M., Saha, S., White, G., Woollen, J., Zhu, Y., Chelliah, M., Ebisuzaki, W., Higgins, W. Janowiak, J., Mo, K.C., Ropelewski, C., Wang, J., Leetmaa, A., Reynolds, R., Jenne R., Joseph, D., 1996. The NCEP/NCAR 40-year reanalysis project. Bull. Am. Meteorol. Soc. 77, 437-471.

Kurtz, N.T., Markus, T., 2012. Satellite observations of Antarctic sea ice thickness and volume. J. Geophys. Res. 117 (C8), C08025 <http://dx.doi.org/10.1029/ 2012JC008141>

Kwok, R., Rothrock, D.A., 2009. Decline in Arctic sea ice thickness from submarine and ICESat records: 1958-2008. Geophys. Res. Lett., 36.

Lefebvre, W., Goosse, H., 2005. Influence of the Southern Annular Mode on the sea ice-ocean system: the role of the thermal and mechanical forcing. Ocean Sci. 1 , 145-157.

Lefebvre, W., Goosse, H., 2008. Analysis of the projected regional sea-ice changes in the Southern Ocean during the twenty-first century. Climate Dyn. 30, 59-76.

Lefebvre, W., Goosse, H., Timmerman, R., Fichefet, T., 2004. Influence of the Southern Annular Mode on the sea ice-ocean system. J. Geophys. Res. 109 C09005.

Levitus, S., 1998. NODC World Ocean Atlas. <http://www.esrl.noaa.gov/psd/>.

Lindsay, R., Zhang, J., 2006. Assimilation of ice concentration in an ice-ocean model. J. Atmos. Ocean. Technol. 23, 742-749.

Lisæter, K.A., Evensen, G., Laxon, S., 2007. Assimilating synthetic CryoSat sea ice thickness in a coupled ice-ocean. J. Geophys. Res. 112, C07023.

Lisæter, K.A., Rosanova, J., Evensen, G., 2003. Assimilation of ice concentration in a coupled ice-ocean model, using the ensemble Kalman filter. Ocean Dyn. 53 , 368-388.

Liu, J., Curry, J.A., Martinson, D.G., 2004. Interpretation of recent Antarctic sea ice variability. Geophys. Res. Lett. 31, L02205.

Madec, G., 2008. Nemo ocean engine: note du pôle de modélisation de linstitut pierre-simon laplace no 27. <http://www.nemo-ocean.eu/About-NEMO/ Reference-manuals>.

Massonnet, F., Fichefet, T., Goosse, H., Vancoppenolle, M., Mathiot, P., König Beatty, C., 2011. On the influence of model physics on simulations of Arctic and Antarctic sea ice. Cryos. 5 (3), 687-699 <http://www.the-cryosphere.net/5/687/ $2011 />$.

Mathiot, P., Knig Beatty, C., Fichefet, T., Goosse, H., Massonnet, F., Vancoppenolle, M. 2012. Better constraints on the sea-ice state using global sea-ice data assimilation. Geosci. Model Dev. 5 (6), 1501-1515 <http://www.geoscimodel-dev.net/5/1501/2012/>.

Parkinson, C.L., Cavalieri, D.J., 2012. Antarctic sea ice variability and trends, 19792010. Cryos. 6 (4), 871-880 <http://www.the-cryosphere.net/6/871/2012/>.

Richter-Menge, J.A., Perovich, D.K., Elder, B.C., Claffey, K., Rigor, I., Ortmeyer, M. 2006. Ice mass-balance buoys: a tool for measuring and attributing changes in the thickness of the Arctic sea-ice cover. Ann. Glaciol. 44, 205-210.

Rothrock, D.A., Percival, D.B., Wensnahan, M., 2008. The decline in arctic sea-ice thickness: separating the spatial, annual, and interannual variability in a quarter century of submarine data. J. Geophys. Res. 113, C05003.

Sakov, P., Bertino, L., 2010. Relation between two common localisation methods for the EnKF. Comput. Geosci. 15, 225-237.

Schweiger, A., Lindsay, R., Zhang, J., Steele, M., Stern, H., Kwok, R., 2011. Uncertainty in modeled Arctic sea ice volume. J. Geophys. Res. 116, C00D06.

Semtner, A.J., 1976. A model for the thermodynamic growth of sea ice in numerical investigations of climate. J. Phys. Oceanogr. 6, 379-389.

Shu, Q., Qiao, F., Song, Z., Wang, C., 2012. Sea ice trends in the Antarctic and their relationship to surface air temperature during 1979-2009. Climate Dyn. 38 (11-12), 2355-2363 <http://dx.doi.org/10.1007/s00382-011-1143-9>.

Stammerjohn, S., Massom, R., Rind, D., Martinson, D., 2012. Regions of rapid sea ice change: an inter-hemispheric seasonal comparison. Geophys. Res. Lett. 39, L06501.

Stark, J.D., Ridley, J., Martin, M., Hines, A., 2008. Sea ice concentration and motion assimilation in a sea ice ocean model. J. Geophys. Res. 113, C05S91.

Thompson, D.W.J., Solomon, S., 2002. Interpretation of recent Southern Hemisphere climate change. Science 296, 895-899.

Tietsche, S., Notz, D., Jungclaus, J.H., Marotzke, J., 2012. Assimilation of sea-ice concentration in a global climate model - physical and statistical aspects. Ocean Sci. Discuss. 9 (4), 2403-2455 <http://www.ocean-sci-discuss.net/9/2403/ $2012 />$.

Timmerman, R., Goosse, H., Madec, G., Fichefet, T., Éthé, C., Dulière, V., 2005. On the representation of high latitude processes in the ORCA-LIM global coupled sea ice-ocean model. Ocean Modell. 8, 175-201.

Timmerman, R., Worby, A.P., Goosse, H., Fichefet, T., 2004. Utilizing the aspect sea ice thickness data set to evaluate a global coupled sea iceocean model. J. Geophys. Res. 109, C07017.

Trenberth, K.E., Large, W., European Centre for Medium Range Weather Forecasts, 1989. A global ocean wind stress climatology based on the ECMWF analyses. <http://dss.ucar.edu/datasets/ds110.1/> 
Turner, J., Comiso, J.C., Marshall, G.J., Lachlan-Cope, T.A., Bracegirdle, T., Maksym, T., Meredith, M.P., Wang, Z., Orr1, A., 2009. Non-annular atmospheric circulation change induced by stratospheric ozone depletion and its role in the recent increase of Antarctic sea ice extent. Geophys. Res. Lett. 36, L08502.

Vancoppenolle, M., Fichefet, T., Goosse, H., Bouillon, S., Madec, G., Morales Maqueda, M.A., 2009. Simulating the mass balance and salinity of Arctic and Antarctic sea M.A., 2009. Simulating the mass balance and salinity of Arctic and Ant
ice. 1: Model description and validation. Ocean Modell. 27, 33-53.

Vancoppenolle, M., Timmermann, R., Ackley, S.F., Fichefet, T., Goosse, H., Heil, P., Leonard, K.C., Lieser, J., Nicolaus, M., Papakyriakou, T., Tison, J.-L., 2011. Assessment of radiation forcing data sets for large-scale sea ice models in the Southern Ocean. Deep Sea Res. Part II: Topical Stud. Oceanogr. 58, 1237-1249 <http://www.sciencedirect.com/science/article/B6VGC-51H1DFT-1/2/e23e88982 e9a3a6d2d034a18c825a7db>.

Worby, A.P., Geiger, C.A., Paget, M.J., Woert, M.L.V., Ackley, S.F., DeLiberty, T.L., 2008. Thickness distribution of Antarctic sea ice. J. Geophys. Res. 113, C05S92.
Xie, P., Arkin, P.A., 1997. Global precipitation: a 17-year monthly analysis based on gauge observations, satellite estimates, and numerical model outputs. Bull. Am. Meteorol. Soc. 78-11, 2539-2558.

Yi, D., Zwally, H.J., Robbins, J.W., 2011. ICESat observations of seasonal and interannual variations of sea-ice freeboard and estimated thickness in the Weddell Sea, Antarctica (2003-2009). Ann. Glaciol. 52 (57), 43-51.

Zhang, J., 2007. Increasing Antarctic sea ice under warming atmospheric and oceanic conditions. J. Climate 20, 2515-2529.

Zhang, J., Thomas, D.R., Rothrock, D.A., Lindsay, R.W., Yu, Y., Kwok, R., 2003. Assimilation of ice motion observations and comparisons with submarine ice thickness data. J. Geophys. Res. 108 (C6), 3170.

Zunz, V., Goosse, H., Massonnet, F., How does internal variability influence the ability of CMIP5 models to reproduce the recent trend in Southern Ocean sea ice extent?, The Cryosphere Discussions, 6, 3539-3573.

Zwally, H.J., Yi, D., Kwok, R., Zhao, Y., 2008. ICESat measurements of sea ice freeboard and estimates of sea ice thickness in the Weddell Sea. J. Geophys. Res. 113 (C2), C02S15 <http://dx.doi.org/10.1029/2007JC004284>. 